\title{
O DESENVOLVIMENTO DA COMPETÊNCIA INTERCULTURAL PRAGMÁTICA E OS ESTEREÓTIPOS NO ENSINO DE ELE
}

\section{THE DEVELOPMENT OF INTERCULTURAL COMPETENCE PRAGMATIC AND STEREOTYPES IN SPANISH TEACHING AS A FOREIGN LANGUAGE}

\author{
Crisbelli Domingos 1 \\ Universidade Federal do Paraná \\ Elena Godoy 2 \\ Universidade Federal do Paraná
}

Resumo: O objetivo neste trabalho é demonstrar que o desenvolvimento de uma competência intercultural pragmática e os estereótipos no ensino de ELE são mais amplamente entendidos, tanto em seus conceitos particulares como na relação entre eles, quando observados a partir da ideia de atração cultural. A teoria de Sperber (2012) e Claidière, Scott-Phillips e Sperber (2014) visa à descrição causal e natural dos fenômenos culturais, e o ensino, especificamente o de língua adicional, oferece elementos observáveis a partir dessa descrição, entre eles o apontamento dos atratores que contribuem para a própria evolução cultural.

Palavras-Chave: Competência Pragmática; Interculturalidade; Ensino de ELE; Estereótipos, Atração Cultural.

1 Endereço eletrônico: crisbelli.domingos@hotmail.com

2 Endereço eletrônico: elena.godoi@gmail.com 
Abstract: The objective of this work is to demonstrate that the development of a pragmatic intercultural competence and stereotypes in Spanish teaching as a foreign language are more widely understood, both in their particular concepts and in the relationship between them, when observed from the idea of cultural attraction. The theory of Sperber (2012) and Claidiere, Scott-Phillips e Sperber (2014) aims at the causal and natural description of cultural phenomena, and teaching, specifically that of additional language, offers observable elements from this description, among them the appointment of the attractors that contribute to the cultural evolution itself.

Keywords: Pragmatic Competence; Interculturality; ELE teaching; Stereotypes, Cultural Attraction.

\section{INTRODUÇÃO}

O ensino de língua estrangeira, neste caso ELE, pressupõe umaabordagem intercultural para a aquisição de um conjunto de experiências e aptidões que capacitem os alunos à ação e a tomada de decisões adequadas à proposta de uma sociedade pluricultural e multilíngue. No entanto, a aplicação desse princípio não é assim tão simples: requer que o aluno tenha consciência doseu próprio significado social para que, a partir de uma estrutura cognitiva sistematizada, possa sistematizar outras, identificando, interpretando e intuindoas diferenças e as semelhanças.

Não são raros os choques culturais durante o aprendizado de uma nova língua e de uma nova cultura. Os estereótipos, segundo Godoy (2001), são um exemplo de dissonância representativa entre culturas, principalmente quando considerados como embriões de preconceito, mais fracos e talvez mais flexíveis à mudança quando houver a experimentação. Apesar da essência negativa pelo reducionismo que carrega em si, procuramos demonstrar neste trabalho que o estereótipo pode ser uma ferramenta útil para a reflexão sobre uma nova língua, dentro de uma proposta construída a partir da interculturalidade. Isto é, os estereótipos são elementos que podem contribuir para tornar as variantes culturais mais atrativas no ensino.

Com base nisso, apresentamos o conceito de atração cultural no ensino a partir de teorias que dialogam com a pragmática cognitiva, e descrevemos como 
essa concepção pode lançar luz sobre o desenvolvimento da competência pragmática do aluno, a partir do manejo de diferenças e choques culturais.

\section{ATRAÇÃO CULTURAL E ENSINO}

Dawkins (1967) introduziu a ideia de unidade de transmissão cultural capaz de se replicar e de se submeter à seleção evolutiva. Sperber (2012) descreve que a existência dessas unidades só é possível a partir de uma concepção de atração cultural. Cada cultura possui suas próprias convenções, crenças, normas sociais, mitos, símbolos, ideologia, rituais e ferramentas que são continuamente (re)produzidas. No entanto, apesar de as práticas culturais serem dinâmicas, porque variam no tempo e no espaço, é inegável que permaneçam semelhantes, afinal “(...) uma sopa Irlandesa é uma sopa Irlandesa, a Chapeuzinho Vermelho é a Chapeuzinho Vermelho e samba é samba" (SPERBER, 2012, p. 01, tradução nossa $)^{3}$.

A tendência é acreditar que essa estabilidade no nível macro cultural possa vir de uma espécie de fidelidade micro cultural, interindividual. Porém, o que Sperber (2012) e Claidière, Scott-Phillips e Sperber (2014) observam é que há uma mistura entre preservação de modelos e construção de versões adequadas às capacidades e interesses culturais dos interlocutores. Os artefatos epistêmicos se tornam semelhantes entre indivíduos não porque são replicados repetidas vezes de maneira fidedigna ao seu molde inicial, mas porque são modificados, reconstruídos atendendo ao objetivo de atrair culturalmente os indivíduos.

Os atratores culturais atendem a um princípio de eficiência: são comunicados com o objetivo de enriquecer as representações dos indivíduos em

\footnotetext{
3 These items remain self-similar over social space and time: in spite of variations, an Irish stew is an Irish stew, Little Red Riding Hood is Little Red Riding Hood and a samba is a samba (SPERBER, 2012, p. 01).
} 
conformidade com o contexto, isto é, causam um efeito cognitivo atrativo, que evoca símbolos para melhores interpretações. Isso se estende desde a evolução biológica à cultural.

Kline (2015) apresenta uma proposta descritiva entre atração cultural e ensino, demonstrando que a própria função do ensino é fazer com que o conteúdo ensinado seja um atrator. Quando explorada a variedade de fatores de atração cultural no ensino, o conteúdo se torna aprendível e ensinável. Assim, os atratores culturais desempenham um papel importante na transmissão do conhecimento cultural.

Entretanto, a autora sugere que os mecanismos psicológicos responsáveis por transformar conteúdos específicos em atraentes - não acompanham a velocidade de mutação das representações mentais em evolução cultural. Essa constatação de Kline (2015) remete, portanto, a um problema de adaptação cultural, que ela resolveu ao se apropriar da concepção de Csibra e Gergely (2011) de que o ensino é uma forma única de adaptação universalmente humana, isto é, a evolução do ensino é concebida como adaptação, conhecida por pedagogia natural.

Em resposta à pesquisa de Kline (2015), Scott-Phillips e Sperber (2015) argumentam que na teoria da atração cultural não são considerados apenas os fatores psicológicos de atração, mas também os biológicos e ambientais, situados no tempo e no espaço. Os autores explicam que o ensino ativo envolve um contínuo de variantes, que vão desde aqueles comportamentos usuais que instruem o aluno a reproduzir cópias daquilo que é feito in loco pelo professor, até as instruções verbais que somente descrevem o comportamento (ação) a ser realizado. Obviamente, o aluno não age por mera imitação e o ensino não se reduz a reprodução de cópias, mas cada estudante, em sua condição de indivíduo pertencente a seu grupo social, possui em si uma natural preservação de modelos e construção de versões adequadas às suas capacidades e interesses culturais. 
A transmissão cultural não é uma questão de imitação, mas de uso sistemático de processos conservadores e construtivos. Para Scott-Phillips e Sperber (2015), ensinar qualquer variante cultural impacta mais na variante do que no ensino em si. Em outras palavras, o ensino das variantes culturais contribui para torná-las atrativas e essa é, justamente, a função do próprio ensino. As habilidades de ensinar e de aprender com o ensino são fatores cruciais de atração cultural e o professor deve tirar vantagem dos fatores disponíveis.

Como prática cultural, o ensino ilustra a dimensão da evolução cultural. Isso acontece porque o ensino tem como objetivo ampliar a frequência das variantes culturais e se apoia, para ter sucesso, em fatores de atração cultural. Observar o ensino de língua estrangeira a partir do processo evolutivo da cultura e vice versa pode possibilitar um melhor entendimento sobre a importância do desenvolvimento da competência pragmática nos alunos. Esse é o tema do tópico a seguir.

\section{COMPETÊNCIA INTERCULTURAL NA AQUISIÇÃO DE ELE EOS ESTEREÓTIPOS CULTURAIS}

Jordán (2001) define a aprendizagem intercultural como propícia à aquisição de um conjunto de experiências e aptidões, que capacitam indivíduos para a ação e a tomada de decisões adequadas e compatíveis com a proposta de uma sociedade multicultural e multilíngue. Aprender uma língua estrangeira possibilita a consciência do indivíduo, em seu contexto, sobre a construção do seu próprio significado social. Quando essa significação é colocada como base no ensino, o aluno adquire não apenas a competência linguística desejada, mas também a competência ${ }^{4}$ cultural direcionada à aproximação com a cultura do

\footnotetext{
4 Consideramos competência comunicativa como o conhecimento que detém a linguagem como instrumento de comunicação em um determinado contexto social, em suas negociações de significados entre os interlocutores, a fim de atingir uma comunicação bem-sucedida.
} 
outro, estimulando entendimento, interpretação, colaboração e respeito pelas diferenças.

Nesse sentido, discutiremos a seguir como os estereótipos culturais provocam uma dissonância entre duas culturas: o que é pensado e acreditado por um grupo de pessoas dentro da cultura nativa, nem sempre corresponde às práticas da cultura observada. Abordar essas diferenças pode ser benéfico para a desconstrução de preconceitos, para atualização de conhecimentos sobre diferentes realidades culturais e para o enriquecimento de representações de mundo na propagação natural da evolução cultural.

\subsection{Competência intercultural na aquisição de ELE}

Com base na dicotomia de Chomsky (1965) sobre competência e desempenho na língua materna, são incontáveis os autores ${ }^{5}$ das ciências sociais, da filosofia e da linguística que oferecem propostas teóricas que envolvem a combinação de diferentes tipos de competências dentro de uma competência comunicativa geral, incluindo competências específicas para a aquisição de línguas estrangeiras. Somente a partir dos anos 90, e em maior número depois dos anos 2000, é que houve a incorporação da competência intercultural nosestudos do ensino de línguas, descrita por diferentes vieses científicos: o pedagógico, o social, o cultural, o linguístico e o cognitivo. Instituíram-se diferentes abordagens teóricas, mas poucas ofereceram um olhar múltiplo capazde integrálos rumo à construção de uma proposta mais robusta, de cunho psicosociocognitivo da significação linguística e cultural.

5 A título de exemplo destacamos Hymes (1979) e a dicotomia entre competência e atuação; Canale (1995) e sua apresentação de quatro diferentes competências: gramatical, sociolinguística, discursiva, estratégica; Van Ek (1986), que somou à lista de Canale outras duas competências, a sociocultural e a social; Kramsch (1998) e a descrição da língua como condutor sociocultural; Ratner (1995) e a concepção de consciência social como âncora da consciência cultural; entre vários outros cientistas interessados no tema. 
O estudo seminal de Godoy (2001) sobre a ideia de competência intercultural no ensino de língua e cultura espanhola no Brasil demonstrou uma introdução à integração desses vieses, por ser ancorado em uma perspectiva pragmática de linguagem. Na época, a pragmática cognitiva ainda não existia no Brasil e estava pouco disseminada no mundo. Porém, um escasso acesso aos estudos das ciências da cultura e da mente permitiu a construção de conceitos (apresentados no tópico 3), em que a cultura é explanada a partir de múltiplos aspectos comportamentais humanos na linguagem e na aquisição de línguas estrangeiras, considerando a pluralidade epistêmica como núcleo da organização comunitária e linguística na América Latina.

Segundo Godoy (2001), a cultura latino-americana, do ponto de vista histórico, foi transformada pela colonização espanhola, tornando-se ferramenta de dominação. O processo evolutivo de adaptação cultural remontou novas práticas linguísticas, e, com isso, instituíram-se outras variações do idioma. Esse pensamento é possível quando considerado o conceito sociológico de cultura, como um conjunto de normas, valores, tradições, crenças e instituições partilhadas numa mutualidade coletiva de mentes, que distinguem e se distinguem como membros de um grupo. Assim, conforme afirma Dascal (1999), a competência linguística se mostra 'socio-psico-pragmática' (tanto na língua materna, como na estrangeira), em que a profundidade da aquisição se torna intimamente ligada ao grau de familiaridade do indivíduo com a cultura, isto é, com as normas e valores presentes nessas estruturas cognitivas de determinados grupos sociais.

A cultura no ensino de espanhol como língua estrangeira (ELE) é aspecto chave para o êxito da comunicação, porque o conhecimento partilhado de mundo é crucial no entendimento das formas oral e escrita do discurso. Para Godoy (2001), esse é, justamente, o cerne de uma competência intercultural pragmática, que existe quando um membro de uma comunidade sabe reconhecer e 
interpretar eficientemente o comportamento verbal de outros, e também o seu próprio, segundo alguns critérios que permitem avaliar se esse comportamento é possível (no sentido gramatical), se é praticável (no sentido psicológico) e se é de uso reconhecível (no sentido sociocultural) (GODOY, 2001, p. 325).

Estudantes de línguas aprendem a se comunicar mais facilmente quando são apresentadas gramáticas didáticas, com explicações linguísticas contextualmente acessíveis. Nesse ponto, a prática pedagógica (de aqui em diante, prática de ensino) depende, de forma estrita, da inclusão da abordagem (inter)cultural para que a mediação do conhecimento - tanto pelo material, como pelo professor e o planejamento do curso de modo geral -, atinja a objetivo primordial que é apresentar a outra cultura não como 'melhor' ou 'pior' que a cultura nativa, mas como apenas uma das múltiplas expressões da natureza humana, que, por meio da língua, se abre para a possibilidade do conhecimento. Para Godoy (2001), o conhecimento intercultural faz com que não se absorva (entenda, interprete, intua) apenas uma nova informação lexical,gramatical e fonética, mas também permite o enriquecimento de umacompetência orientada para adquirir novos elementos simbólicos de umacomunidade diferente. As palavras não são simplesmente novos rótulos paravelhos conceitos, a nova gramática não é simplesmente uma nova maneira declassificar e categorizar, e as novas pronúncias não são somente maneirasdiferentes de articular os sons. Tudo isso faz parte das características culturais de uma outra comunidade linguística.

A competência intercultural, ou socio-psicopragmática (DASCAL, 1999), é ou pode ser desenvolvida no ambiente natural e/ou no ambiente de ensino formal. No ensino formal, são trazidas as diferenças e as estruturas linguísticas que se ligam com seus significados em um contexto histórico e sociocultural particular (GODOY, 2001, p. 326). O professor pode, constantemente, aprofundar entendimentos sobre ambas as culturas, materna e estrangeira, pelo manejo de 
fontes que ajudam na identificação e na análise dos padrões culturais. Para Godoy (2001), é indispensável que no ensino de ELE sejam introduzidos diálogos contextualizados, ou seja, que façam o estudante inferir aquilo que é ou não adequado à prática discursiva das (ou entre as) diversas culturas hispano falantes (espanhola, porto-riquenha, cubana, colombiana, argentina, chilena, uruguaia, etc.), apresentando os comportamentos comunicativos em diferentes práticas (informal, familiar, profissional), que remetem ao conhecimento necessário de algumas das tantas idiossincrasias inerentes dos grupos humanos.

Concomitante a esse caminho cultural-pedagógico do contexto formal, há a aquisição da linguagem coloquial de ELE, que é onde as coisas se complicam. Godoy (2001) pontua que o cotidiano apresenta pelo menos duas ramificações básicas. Por um lado, existe o universo daquilo que é comum em muitas sociedades: a política, a economia e os fenômenos de interesse mundial, através da lente particular de uma comunidade. E do outro lado, a perspectiva particular das pessoas, aninhadas no caráter íntimo que compõe a vida afetiva e psicológica de cada indivíduo.

No plano individual, segundo Godoy (2001), há uma forte tendência humana à crença de que a cultura nativa seja universal, e que critérios de valores, de classificações e de categorizações de representações sobre o mundo, convencionadas no grupo nativo (regional, nacional ou os vários outros menores), sejam os únicos possíveis e comuns a todos. Essa tendência social, portanto humana, pode causar a ingênua impressão de que basta aprender um razoável número de palavras numa língua estrangeira, para conseguir usá-las no lugar das palavras da língua materna, e pronto! Já se sai por aí falando uma nova língua.

Há universalidade na estrutura dos processos cognitivos humanos, mas existem diferenças na percepção, segmentação e categorização do mundo real pelas diferentes representações das diferentes comunidades culturais. Godoy 
(2001) afirma que essas diferenças refletem diretamente na língua, e esse reflexo é um dos pilares da identidade do indivíduo como cidadão e da comunidade como formação social. Não existe identidade sem a legitimação do contraste da diferença do outro. A consciência de não ser o outro é o que confirma a identidade individual e coletiva.

Uma comunidade linguística, e por isso cultural, pode ser entendida como um "indivíduo" composto de muitos outros indivíduos, como um conjunto de indivíduos particulares. Assim, a cultura é memória (talvez também genética) de uma comunidade materializada e presente, em maior ou menor grau, nas personalidades linguísticas de seus integrantes. Cada personalidade linguística é única, tem o seu próprio espaço cognitivo e conhecimento da língua e das particularidades de seu uso, mas há uma parte dessa personalidade ocupada por uma invariante, que determina a pertença do indivíduo a uma comunidade linguístico-cultural (GODOY, 2001, p. 327).

Por essa razão, o desenvolvimento da competência intercultural pragmática do aluno depende da partilha dos conhecimentos básicos que estão disseminados nas mentes da maioria dos falantes da língua que está sendo aprendida, no caso, o espanhol. Além disso, Godoy (2001) explica que esses conhecimentos devem ser mediados de maneira que o aluno entenda que essas representações de mundo, aceitas e partilhadas pelos hispano falantes, não são verdades absolutas, corretas entre os nativos e incorretas no geral. $\mathrm{O}$ fundo cultural-associativo que estrutura e constitui o enunciado é que precisa ser entendido, segundo o contexto da língua.

Mesmo que essa a prática de abordar o contexto de uso da língua seja clara para o ensino de ELE, não se pode negar a ocorrência de "choques culturais" durante o processo de aprendizagem. A falta de coincidência entre fenômenos culturais faz com que haja comparação entre o que é 'normal' e o que é 'estranho', o que é 'certo' e o que é 'errado', e isso pode causar desconfortos interpretativos 
que podem, inclusive, desmotivar o aprendizado da língua, se não houver transformação e adaptação desses fenômenos para temas de debates e discussões. Esse é, por exemplo, o caso dos estereótipos culturais que trataremos a seguir.

\subsection{Os estereótipos culturais}

Ser professor de língua, cultura e literatura espanhola não é tarefa fácil. $\mathrm{O}$ nível de sofisticação da competência intercultural do professor é (ou deveria ser) demasiadamente alto, porque envolve o contraste e a comparação entre diferentes mundos hispanos, sobre os seus regimes políticos, as histórias, as comidas, as festas, as crenças, os costumes, e, obviamente, as expressões linguísticas particulares. Esses elementos das organizações humanas ajudam na construção de representações, que permitem a interpretação de fenômenos linguísticos que inquietam e interessam aos alunos.

Trabalhar com esses múltiplos conhecimentos culturais proporciona, inescapavelmente, o contato com ideias pré-concebidas sobre a língua e a cultura, como os estereótipos culturais, dos mais diversos tipos: "espanhol é fácil e não precisa estudar muito", "o espanhol peninsular é o estândar, é o melhor", "os falantes nativos são os melhores professores".

Como se formam os estereótipos? Como as capacidades mentais humanas não são infinitas, as informações são armazenadas por relevância: lembramos e atualizamos representações conforme a nossa interação com o contexto atual. Por essa razão, sabemos mais sobre aquilo que particularmente nos interessa, e menos sobre todas as outras milhares de coisas que nos circundam, que por sua irrelevância (para nós) não nos atraem.

Na concepção de cultura, o encontro com o outro é sempre mediado por processos de categorização, cristalização de imagens e classificação. É o que nossas mentes humanas fazem para criar e armazenar informações, e isso é parte 
inerente da estereotipia. Nossas interações com o meio em que vivemos, com os grupos de que fazemos parte, permitem a criação de representações mentais partilhadas semelhantes entre alguns ou entre todos. Esse fenômeno criativo, linguístico e essencialmente cultural faz com que criemos 'traços' sobre informações que, manifestadas e repetidas nas relações grupais, se tornam enrijecidas.

A etimologia da palavra 'estereótipo' é de origem grega, formada por 'stereós', que significa rígido, sólido, e 'typos', que significa tipo (GODOY, 2001, p. 334). Designa a conotação psicossocial feita sobre pessoas ou grupos depessoas atribuindo-lhes características que, com o tempo, acabam se tornando rígidas e homogêneas. Essas características são identificadas, observadas e nomeadas a partir do caráter coletivo de um conceito pré-elaborado, conforme ojulgamento sobre um padrão ou comportamento cultural que é diferente, ou interpretado como diferente, do comportamento social da cultura de origem. Essa préelaboração se origina do desconhecimento da outra cultura e de suas práticas.

Esse reducionismo cultural e cognitivo que emoldura a estereotipia, nos leva a definição de Espinosa (1993), de que o estereótipo é um mapa cognitivo que simplifica uma realidade pouco conhecida, para que essa realidade seja de alguma forma entendível, interpretável.

Por seu caráter individual e coletivo que generaliza e simplifica, e por se dispersar sobre as mais variadas impressões culturais, a atuação do estereotipo pode se materializar e se difundir em múltiplos níveis e escalas de propagação. Não é objetivo deste trabalho oferecer uma proposta de tipificação, classificação ou categorização de padrões de estereótipos culturais, sequer é possível fazer isso (e se fosse, não vemos usabilidade), mas identificamos três importantes níveis de profundidade para o nosso recorte: o individual, o cultural e o macro cultural.

No nível individual, em Godoy (2001), é definido que os estereótipos nascem no formato de afirmações que comunicam ou justificam as próprias 
concepções de mundo, as opiniões particulares, as hipóteses não confirmadas e as suposições fracas para que assim exista, amparando-se num pilar real ou ilusoriamente coletivo, algum tipo de alívio cognitivo no cometimento de ações estereotipadas. Isso acontece, por exemplo, na afirmação tão comum entre os aprendizes de espanhol: "espanhol é fácil e não precisa estudar muito".

No nível micro cultural, que acopla o individual, os estereótipos são usados para justificar ações coletivas. Outra afirmação difundida é de que "os falantes nativos são os melhores professores". Sabemos que há no Brasil um segmento de pessoas que, interessadas no estudo de um idioma, partilham entre si hipóteses e suposições superficiais sobre aprendizado e cultura, e isso pode se retroalimentar, difundir e se agravar até a prática do preconceito. Não é raro encontrar nas mídias, redes sociais e outdoors, propagandas de escolas de idiomas com o discurso "temos somente professores nativos" em suas peças de divulgação. Esse é um caso nítido - entre tantos outros - da publicidade tirando proveito de estereótipos desrespeitosos, por saber que são partilhados por um número substancial de pessoas. As ações publicitárias amplificam a disseminação do estereótipo, que tanto é reforçado no grupo social que o possui, como propagado para outras mentes que armazenam uma informação cultural negativa, como sendo positiva e real6.

O nível macro cultural, que engloba o individual e o micro cultural, aporta estereótipos usados para explicar sistemas sociais nacionais, servindo de justificativa para as estruturas da sociedade. São relacionados às comparações sociais, econômicas, políticas, históricas e religiosas entre grupos de diferentes países, que criam e propagam estereótipos que desfavorecem a sua nação ou a nação do outro. Para o contexto do debate deste artigo, um exemplo de

\footnotetext{
6 Acreditamos, inclusive, que o estereótipo é um fenômeno observável pela Teoria da Epidemiologia das Representações (SPERBER, 1985), mas por uma questão de recorte neste artigo não será possível abordar a teoria.
} 
estereótipo que se aproxima é "o espanhol peninsular é o estândar, é o melhor". O pensamento colonial é ainda muito recorrente no Brasil, sendo esse estereótipo a soma de outros como "A língua espanhola falada na Espanha é soberana”, "Os países europeus são superiores". Esse estereótipo desfavorece, ofende e mina a identidade social de todos os outros países que falam a língua espanhola em sua variante cultural, e reforça o reflexo da violência simbólica de uma classe que dominou financeiramente e impôs sua a cultura (BORDIEU, 1974).

Esses níveis mostram como os estereótipos se aproximam do preconceito. Os dois são primos na família dos devastadores culturais. A diferença entre o preconceito e os estereótipos é que alguns deles não são necessariamente negativos, como "todos os japoneses são inteligentes", "toda comida italiana é boa", "todas as brasileiras têm samba no pé", "os brasileiros são bons de bola", "os franceses fazem bons perfumes". Mas, quando são negativos, apesar de serem cruéis e desrespeitosos em essência, são geralmente demonstrados pelos comunicadores como embriões de preconceito: mais fracos e talvez mais flexíveis à mudança quando houver a experimentação. Afinal, durante a vida o indivíduo poderá conhecer japoneses que não são bons em matemática, comprar uma comida italiana impalatável, ver numa roda de samba uma brasileira que não sabe sambar, ganhar um perfume francês ruim. O caráter genérico, hipotético do estereótipo é como uma impressão cristalizada, que com o tempo pode, ou não, se quebrar.

No ensino de ELE, o processo de análise e reelaboração dessas informações, conceitos e representações, se inclui em um outro processo de ensino e aprendizagem, que contraria a manutenção da visão estreita que o aluno apresenta quando comunica um estereótipo. Esse estudante, assim como qualquer outro indivíduo, interage com padrões que regem seus comportamentos, suas percepções da realidade, e vêm de uma hierarquia moral (familiar e/ou social) sobre aquilo que é ou não aceitável. 
Manejar um estereotipo significa entrar nos valores e crenças que governam aspectos da vida diária do aluno. Cada indivíduo constrói os seus esquemas culturais com os membros de sua comunidade e quando enfrenta outros tipos de representações, traz a superfície cognitiva os seus esquemas, analisa e avalia as representações diferentes das suas. É esse caminho cognitivo que precisa ser estimulado pelo professor. Se uma ideia nova for imposta, a chance de repelir e reforçar a sua representação inicial de mundo é alta. Mas se a ideia for experimentada pelo aluno, certamente a representação que ele tem será enriquecida com novos elementos.

Como fazer isso? No tópico anterior, enquanto explanávamos a competência intercultural na aquisição de ELE, pontuamos os elementos chave para um ensino pautado na interculturalidade. Entre esses elementos, o argumento de que uma abordagem intercultural que inclui a apresentação de uma cultura não como 'melhor' ou 'pior', mas como uma das incontáveis expressões da natureza da vida humana, abre a possibilidade do conhecimento, desconstruindo naturalmente as estereotipias. Assim se rompe a forte tendência humana de acreditar que a cultura nativa seja universal.

O professor que aprofunda entendimentos sobre ambas as culturas, materna e estrangeira, facilita a identificação e a análise dos padrões culturais 'diferentes', inclusive para o entendimento de que cada comunidade de fala possui os seus. Possibilitar que o aluno crie mais uma personalidade linguística, mergulhada nos mares, lagos e rios culturais da outra língua, significa promover a partilha dos conhecimentos básicos que estão disseminados nas mentes da maioria dos falantes da L2, de maneira a interpretar e respeitar as peculiaridades dos diferentes grupos culturais.

O ambiente formal de aprendizagem é um lugar apropriado e contextualmente adaptado para ser um espaço natural de diálogos, trocas de ideias, debates. Godoy (2001) explicita que o ensino de ELE é completamente 
ancorado na interculturalidade e tem como objetivo desenvolver, enriquecer e reforçar a competência intercultural, e por isso pragmática, para a aquisição da língua. O aparecimento de estereótipos e preconceitos é inerente ao ensino de línguas. Tanto os cursos superiores de formação de professores, como vários dos livros didáticos usados pelos alunos, abordam os estereótipos culturais e o preconceito sistemático e cultural. Durante essas práticas de ensino, ou quando do aparecimento de atitudes estereotípicas, preconceituosas ou de intolerância pelos alunos com relação à cultura estrangeira, como dito acima, novos caminhos cognitivos precisam ser estimulados pelo professor, de modo que a nova ideia seja experimentada pela reflexão, não pela imposição.

A pesquisa de Kraviski (2007) mostra que o desenvolvimento de uma competência intercultural pragmática nos alunos, descrito neste artigo, foi capaz de dissolver talvez um dos mais fortes estereótipos macro culturais da América Latina, que é a rivalidade entre brasileiros e argentinos. Vários setores da "Indústria Cultural" (KRAVISKI, 2007, p. 61) estimularam o fortalecimento desse estereótipo, principalmente pela história futebolística das duas nações, marcada no início da década de 90 por Diego Maradona, que era comparado e se comparava a Pelé, pois ambos eram os admirados camisa 10 dos respectivos times nacionais. A criação midiática de uma rivalidade entre o desempenho dos dois em suas equipes aqueceu o esporte, movimentou campeonatos, aumentou audiência de rádio e TV, favoreceu publicitários, mas não foi culturalmente benéfica para os povos. Até hoje o reflexo desse estereótipo intercultural hereditário e sistemático paira entre os países e os países vizinhos, de forma generalizada entre classes, idades e gêneros, se aproximando do que entendemos como preconceito e xenofobia.

Os dados de Kraviski (2007) são muitos e divididos em três partes.

\footnotetext{
7 Apresentado esse contexto, Kraviski é argentina e decidiu dar aulas de língua espanhola em uma Instituição de Nível Superior no Brasil, no Estado do Paraná, que é fronteiriço ao seu país de origem e possuí a estereotipia de rivalidade ainda mais saliente. Nos anos de 2006 e 2007,
} 
Selecionamos apenas quatro, que se relacionam diretamente ao estereótipo mencionado. Eles mostraram que dos alunos da instituição em que Kraviski dava aulas, denominada B, 27,03\% (de 50\%, método Survey) se identificaram com a variante argentina, $10,81 \%$ com a variante peninsular e outros 10,81\% declararam-se indiferentes sobre a escolha de variações. Na instituição B, 63\% dos alunos escolheriam a Argentina para estudar espanhol, 32\% a Espanha e 5\% o Chile. Na instituição B, 36,97\% (de 40\%, método Survey) dos alunos possuíam uma impressão positiva sobre os argentinos. Dos adjetivos mais votados, destacam-se: amável, simpático, competente, extrovertido e trabalhador. Na IES B, mais de $80 \%$ dos alunos identificaram abordagens culturais no livro didático. Chega-se à constatação de que a abordagem de ensino do professor, a partir do desenvolvimento do desempenho da capacidade intercultural e pragmática em seus alunos, é capaz de abrir a possibilidade do conhecimento, desconstruindo naturalmente as estereotipias.

\section{O ESTEREÓTIPO NO ENSINO DE ELE E A ATRAÇÃO CULTURAL}

Sperber (2012) e Claidière, Scott-Phillips e Sperber (2014) demonstram na teoria da atração cultural que as práticas culturais são dinâmicas, mas permanecem semelhantes em algum grau. Essa estabilidade ocorre porque há uma mistura entre preservação de modelos e construção de versões adequadas às capacidades e interesses culturais do indivíduo. No ensino de língua estrangeira, esse princípio pode ser observado por algumas razões.

No estudo de Godoy (2001) é explicada a importância de o aluno ter,

depois de já ter enfrentado dar aulas em uma das duas IES usadas na coleta de dados, Kraviski escreveu a sua dissertação de mestrado intitulada Estereótipos culturais: o ensino de espanhol e o uso da variante argentina em sala de aula, orientada por Elena Godoy e embasada nas ideias do citado artigo seminal de 2001. 
primeiramente, a consciência do seu significado social para então desenvolver uma competência cultural que o torne capaz de ser atraído ao aprendizado sobre outra cultura, a fim de entendê-la, adequá-la aos seus interesses de conhecimento, respeitando as diferenças. Se não houver nas práticas culturais a preservação de modelos e a construção de versões adequadas, não existirá consciência do próprio significado social do indivíduo-aluno, estável o suficiente para permitir que ele faça novas conexões sobre novas realidades culturais. Essa relação entre preservação de modelos e construção de versões adaptáveis também incide na avaliação que o aluno precisa fazer sobre se o comportamento social e linguístico na/para outra cultura é, para ele, possível (no sentido gramatical), praticável (no sentido psicológico) e se é de uso reconhecível (no sentido sociocultural). Uma ideia de adequação precede a ideia de avaliação cultural que, para o aprendizado de uma língua adicional, é basilar.

Sperber (2012) e Claidière, Scott-Phillips e Sperber (2014) ressaltam que na teoria de atração cultural não são considerados apenas os fatores psicológicos, mas também os biológicos e ambientais de atração, situados no tempo e no espaço. Godoy (2001) evidencia as diferentes importâncias dos ambientes no ensino, sendo o formal e o informal inexoravelmente responsáveis para uma concepção de interculturalidade.

A construção de uma competência pragmática é elemento chave do ensino como atrator cultural. Essa competência é desenvolvida no ambiente natural e no ambiente de ensino formal. No ensino formal, são trazidas as diferenças e semelhanças, e as estruturas linguísticas se ligam com seus significados em um contexto histórico e sociocultural particular, oriundos do ambiente natural. Essa relação entre os ambientes permite que o professor aprofunde entendimentos sobre ambas as culturas, materna e estrangeira, pelo manejo de fontes queajudam na identificação e na análise dos padrões culturais. Assim, entendemos que para a perspectiva do ensino não há separação entre fatores psicológicos e biológicos, 
tampouco disparidade de velocidade de evolução cultural entre um e outro conforme sugerido por Kline (2015), porque o fator ambiental pressupõe diferentes variedades desses fatores no tempo e no espaço. E a interculturalidade reside, justamente, na existência dessas variedades, sendo o seu estudo no ensino sistemático contributivo para a própria evolução cultural.

Apesar de discordarmos da sugestão de Kline (2015) apresentada acima, concordamos quando a autora afirma que a própria função do ensino é fazer com que o conteúdo ensinado seja um atrator. Quando explorada a variedade de fatores de atração cultural no ensino, o conteúdo se torna aprendível e ensinável. Assim, os atratores culturais desempenham um papel importante na transmissão do conhecimento cultural. Tudo o que argumentamos no tópico 2 vai de encontro com essa ideia, sendo a interculturalidade e o desenvolvimento de uma competência pragmática fatores que elevam o ensino para a condição de um forte atrator cultural.

A despeito da importância de apresentar esse contraste entre as concepções de Godoy (2001), Sperber (2012), Claidière, Scott-Phillips e Sperber (2014), ScottPhillips e Sperber (2015) e Kline (2015), nosso objetivo neste tópicoé argumentar sobre a afirmação de Scott-Phillips e Sperber (2015) de que o ensinodas variantes culturais contribui para torná-las atrativas e essa é, justamente, a função do próprio ensino. As habilidades de ensinar e de aprender com o ensino são fatores cruciais de atração cultural e o professor deve tirar vantagem dos fatores disponíveis.

Vimos que o estudo da interculturalidade contribui para a própria evolução cultural e que o desenvolvimento de uma competência pragmática no aluno, para o aprendizado da interculturalidade, é fundamental. A sofisticação dessa competência permite que o aluno identifique, interprete e analise diferentes padrões culturais e saiba lidar com as diferenças, respeitando-as. Durante esse processo, alimentado estritamente pela habilidade de manejo 
pragmático, o aluno, além de aprender o léxico e os aspectos gramaticais, dissolve estereótipos, atenuando os "choques culturais" inerentes ao aprendizado de uma nova língua e cultura.

Enquanto os estereótipos são geralmente mal vistos pelos professores no ensino de ELE, entendemos o contrário: que podem ser excelentes ferramentas para a aquisição de uma nova língua, dentro de uma proposta construída a partir da interculturalidade. Isto é, os estereótipos são elementos que contribuem para tornar as variantes culturais mais atrativas no ensino. São atratores culturais que ajudam na transmissão do conhecimento cultural.

É inegável que o aprendizado de uma língua adicional traga uma série de benefícios cognitivos em termos de ampliação de conhecimento linguístico, social e histórico. Os textos, os diálogos, as músicas, os filmes, os exercícios gramaticais e todos os outros recursos para o ensino despertam a motivação do aluno e atuam como ferramentas para alimentar essa motivação para o aprendizado.

No entanto, é inegável que a dissonância cognitiva causada pela diferença de representação de mundo cause um efeito emotivo que atraia a atenção do aluno em maior grau. Esse fenômeno ocorre durante os choques culturais, que, em sala de aula, culminam numa oportunidade para que o professor apresente "uma nova ideia", "uma nova perspectiva", uma nova informação que, por destoar, convida o aluno à análise e a reflexão de seus próprios conceitos e representações. Os estereótipos são capazes de causar esse efeito. Conforme afirmamos anteriormente, se uma ideia nova for imposta, a chance de repelir e reforçar a representação inicial de mundo é alta. Mas se a ideia for experimentada pelo aluno, certamente a representação que ele tem será enriquecida com novos elementos.

Caso o professor consiga orientar o caminho cognitivo do aluno para a experimentação da quebra do seu estereotipo, entram em jogo muitos benefícios: o aluno adquire um novo elemento simbólico de uma comunidade diferente; 
enriquece sua representação mental sobre um tema, anulando uma hipótese fraca e construindo uma nova suposição; entende que existem diferenças entre culturas; passa a saber que generalizações reduzem a sua própria concepção de cultura; aproxima-se da proposta de uma sociedade multicultural; evita ou desconstrói preconceitos; estreita a partilha de conhecimentos com os falantes da língua que está aprendendo, ampliando seu alcance cognitivo-cultural; e, principalmente, fica mais perto de entender que são múltiplas as expressões da natureza da vida humana.

Como vimos, o experimento de Kraviski (2007) demonstrou, pelo resultado de sua coleta de dados, que esses aspectos positivos do ensino de ELE são conquistados quando há quebra de estereótipos, mesmo num contexto que parece ser impossível.

\section{CONSIDERAÇÕES FINAIS}

O desenvolvimento da competência intercultural pragmática e os estereótipos no ensino de ELE são mais amplamente entendidos, tanto em seus conceitos particulares como na relação entre eles, quando observados a partir da ideia de atração cultural. A teoria de Sperber (2012) e Claidière, Scott-Phillips e Sperber (2014) visa à descrição causal e natural dos fenômenos culturais, e o ensino, especificamente o de língua adicional, oferece uma infinidade de elementos que correspondem aos propósitos dessa descrição, entre eles a descoberta dos fatores - ou atratores - que contribuem para a evolução cultural. Esperamos que, com os argumentos construídos nesse estudo, os professores de ELE quebrem algum estereotipo que possam ter sobre a pragmática. Sabemos que abordagens cognitivas muitas vezes envolvem termos 'assustadores', mas a perspectiva em si é capaz de mudar a estrutura, a essência de um mediador de ensino, a partir do momento que ele passe a saber os efeitos que as suas 
abordagens culturais fazem na concepção de mundo e na vida cotidiana de seus alunos. Devemos lembrar que ensinar uma cultura diferente significa promover que o aluno reconheça, cada vez mais, a sua própria. E uma significação social ampla possibilita o mundo que tanto queremos: plural e tolerante às diferenças.

\section{REFERÊNCIAS}

BORDIEU, P. A economia das trocas simbólicas. São Paulo: Perspectiva, 1974.

CANALE, M. De la competencia comunicativa a la pedagogía comunicativa del lenguaje. In: Competencia Comunicativa: documentos básicos en la enseñanza de lenguas extranjeras. Peñalara: Edelsa, 1995.

CHOMSKY, N. Aspects of the theory of syntax. Cambridge, MA: MIT Press, 1965.

CLAIDIÈRE, N; SCOTT-PHILLIPS, T; SPERBER, D. How Darwinian is Cultural Evolution? In: Philosophical Transactions of The Royal Society B, Biological Sciences, 369, 2014, p. 1642-1650.

CSIBRA, G. \& GERGELY, G. Natural pedagogy as evolutionary adaptation. In: Philosophical Transactions of The Royal Society B, Biological Sciences, 366, 2011, p. 1149-1157.

DASCAL, M. Interpretação e compreensão. São Leopoldo: Unisinos, 1999.

DAWKINS, R. O gene egoísta. Cambridge: Harvard University Press. 1976 (1967).

ESPINOSA, L. La mirada del outro: la imagen de España en el extranjero. ICE: Información Comercial Española, n. 722, 1993.

GODOY. E. La Cultura en la enseñanza del español y de las literaturas hispánicas. Anuario Brasileño de Estúdios Hispánicos, V. 1, no 11, 2001.

HYMES, D. H. On Communicative Competence. In: BRUMFIT, C. J; JOHNSON, K. The Communicative Approach to Language Teaching. Oxford: Oxford University Press, 1979.

JORDÁN, J.A. (org). La educación intercultural, una respuesta a tiempo. Barcelona: EDIUOC, 2001.

KLINE, M. A. How to learn about teaching: An evolutionary framework for the study of teaching behavior in humans and other animals. Behavioral and Brain Sciences, Cambridge University Press, 2015, p. 1-71.

KRAMSCH, C. Language and Culture. Oxford: Oxford University Press, 1998.

KRAVISKI, E. R. A. Estereótipos Culturais: o ensino de espanhol e o uso da variante argentina em sala de aula. Dissertação de mestrado, 139 p., Pós-graduação em Estudos Linguísticos, Setor de Ciências Humanas, Universidade Federal do Paraná, 2007.

RATNER, C. A Psicologia Sócio-Histórica de Vygotsky: aplicações contemporâneas. Porto Alegre: Artes Médicas, 1995. 
SCOTT-PHILLIPS, T; SPERBER, D. The mutual relevance of teaching and cultural attraction. Behavioral and Sciences, n. 38, 2015, p. 44-45.

SPERBER, D. Cultural Attractors. In: BROCKMAN, J. (org.) This will make you smarter: new scientific concepts to improve your thinking. New York: Harper Perennial, 2012. VAN EK, J. A. Objectives for foreign language learning. V. 2. Estrasburgo: C. Europe. 1986.

Nota do editor:

Artigo submetido para avaliação em: 30 de setembro de 2020.

Aprovado em sistema duplo cego em: 19 de janeiro de 2021. 